\title{
DERECHO DE FAMILIA, SUCESORIO \\ Y REGÍMENES MATRIMONIALES
}

\section{Leonor Etcheberry Court}

Profesora de Derecho Civil Universidad Diego Portales

RELACIÓN DIRECTA Y REGULAR EN EL MARCO DE LOS ASPECTOS CIVILES DEL SECUESTRO INTERNACIONAL DE NIÑOS. CORte SupRema, 31 dE DiCIEMBRE de 2008.

Don R.S.A. ciudadano estadounidense, representado por la directora de la Corporación de Asistencia Judicial, solicita se regule un régimen comunicacional en su favor en aplicación de la Convención sobre los Aspectos Civiles del Secuestro Internacional de Niños; en relación con el menor C.J.A.S. Dicha acción se dirige en contra de la madre S.E.S.C. El menor de autos tiene en el año 2008, cinco años de edad.

Lo interesante de este fallo es que el demandante no pretende que el menor sea devuelto a su lugar de residencia habitual, sino que pretende que en su calidad de padre del menor, se le fije un régimen comunicacional que le permita tener una buena relación con su hijo, que le servirá como un elemento importante en su desarrollo emocional y afectivo, necesario para su futura actuación como ser humano útil para la sociedad en que viva.

La madre, por su parte, no se opone al régimen en sí, pero quiere que se desarrolle en Chile y bajo supervisión.

Entre los medios de prueba se acompaña por parte del padre un informe sicológico y un informe de la directora del Centro Comunitario de Terapia, que en síntesis señalan que el demandante no evidencia problemas con el manejo de la ira. Por parte de la madre, se acompaña la sentencia del $25^{\circ}$ Juzgado Civil, que condenó al padre a asistir a programa terapéutico en el marco de procedimiento de violencia intrafamiliar, en el año 2005.

El tribunal dispuso un nuevo informe sicológico del menor, la perita fue citada a la audiencia donde señala expresamente:

"el niño no tiene imagen agresiva ni hostil del padre, que la figura de éste le despierta curiosidad"

que

"respecto a la presunta violencia intrafamiliar generada por el padre, tal aserto lo fundó en los dichos de la madre y antecedentes escritos que le 
fueron exhibidos y que no hay secuela de interacción violenta con el padre.

Que la relación del niño con su madre es sana y no simbiótica y le permitir vincularse con otra persona de apego, vale decir, su padre.

Que a su parecer esta relación comunicacional debe darse progresivamente, pero en forma sistemática $y$ ordenada en el tiempo, con un contacto que puede darse en forma no presencial, pero también presencial, con acercamiento autónomo con el padre en nuestro país y que una vez generado el lazo afectivo y de confianza permitirá responsabilidad paterna".

El tribunal de primera instancia, cuya sentencia es ratificada por la Corte de Apelaciones de Santiago, decide que en mérito de las pruebas acompañadas y sobre todo lo señalado por la perita sicóloga, el régimen consistirá en dos semanas en julio y cuatro semanas en enero, debiendo durante el año 2008 y enero de 2009 desarrollarse en Chile, pero sin la necesidad de supervisión. A partir de julio de 2009 se podrá desarrollar en Chile o en Estados Unidos a elección del padre.

Se dedujo por parte de la demandada recurso de casación en el fondo, por infracción al artículo 32 de la ley $\mathrm{N}^{\circ} 19.968$, en este artículo se señala que la apreciación de la prueba debe

realizarse conforme a las reglas de la sana crítica, lo que implica que no pueden contradecirse los principios de la lógica, las máximas de experiencia y los conocimientos afianzados, debiendo hacerse cargo de toda la prueba, incluso de aquélla que se hubiere desestimado.

Según la parte recurrente

"el fallo no ha valorado la totalidad de las probanzas, en especial los informes periciales emitidos por la sicóloga y la asistente social que examinaron la situación del menor y de su madre".

\section{RESPECTO DEL FALLO \\ de la Corte Suprema \\ HAY COSAS IMPORTANTES \\ QUE RELEVAR}

1. La Corte no se hace cargo del hecho de que el juez de primera instancia no oyó al menor en forma directa, lo cual está contraviniendo el artículo 12 de la Convención de los Derechos del Niño, el artículo 242 del Código Civil y el artículo 16 de la ley de Tribunales de Familia; el juez debe (no es facultativo para él) oír al menor atendiendo su edad y madurez, la cual era posible, ya que fue oído por la sicóloga y la asistente social; el juez pudo haber encontrado lo suficiente allí señalado, pero la ley es clara 
en atención a que debe ser oído, pues él directamente podrá hacerse un juicio respecto de los sentimientos del menor hacia su padre, a la posibilidad de estar solo con él, a detectar algún grado de intimidación por su presencia, etc. Lamentablemente el juez no lo hace y la Corte no repara en ello.

Creemos que en muestro país nos falta mucho aún en cuanto a la obligación de oír a los niños y la forma como hacerlo; pero este tipo de fallos que, incluso, se pronuncia sobre el interés superior del niño, sin tomar en cuenta su voluntad, no ayudan a avanzar en el cumplimiento de la Convención de los Derechos del Niño.

2. El menor dejó de tener contacto con su padre desde muy pequeño y sólo a partir de la dictación de una medida cautelar esto pudo revertirse. Aquí habría que preguntarse, ¿̇por qué se produjo esto?, cosa que nadie hace. Después de venirse a Chile con su hijo, la madre adujo un problema de violencia intrafamiliar entre los padres, ante el tribunal, por lo cual el menor no fue devuelto a su lugar de residencia habitual. Esto es algo habitual en nuestro país, que una parte no habiendo denunciado la violencia en su lugar de resi- dencia, sí lo hace en nuestro país; el tribunal lo acogió y el padre fue enviado a terapia, la cual fue cumplida, pues los antecedentes de este juicio son de hace dos años. Durante ese tiempo es la madre quien debió fomentar las relaciones entre el padre y el hijo, aunque fueran a distancia; dada la edad del menor, que lo hace depender de la voluntad de quien lo tiene a su cuidado, es ella quien tiene la responsabilidad de lograr esta comunicación, sin embargo, lejos de eso fue necesario la dictación de una medida cautelar para poder reestablecer el contacto. Con esto queda claro que en cualquier juicio de cuidado personal, uno de los puntos que deben ser tomados en cuenta por el tribunal para decretar este cuidado es cuál de los dos progenitores facilitará la comunicación con el que no tenga el cuidado personal, en este caso, la madre hizo que la relación fuera más distante, quitándole la posibilidad a su hijo de tener una figura paterna tan necesaria para su desarrollo. Lo anterior no fue mencionado ni valorado por la Corte, pues el menor no se ha negado a comunicarse con su padre, sino que, más bien, lo ha idealizado y le provoca curiosidad, no miedo ni angustia. 
3. Respecto al interés superior del niño, la Corte lo menciona en su considerando número 9 , dando un concepto general del mismo, no adaptado al caso en concreto, aunque se reconozca en el considerando siguiente que así debiera ser, no se comprende cómo puede entender la Corte que el interés superior del niño no ha sido considerado debidamente, si no se establece qué es lo que debemos entender por tal. En este caso concreto, la Corte señala que no es "razonable y lógico" que el menor salga al extranjero dada la edad y las circunstancias en que se ha desarrollado la relación entre padre e hijo y, en definitiva, se inclina en favor de los antecedentes aportados por la madre. Es ella la que ha dado los datos negativos del padre; es la madre la que impidió la comunicación, lo que hizo que la relación paterna fuera distante y que necesite un tiempo para reforzar los lazos, es la madre la que se trajo al niño sin la autorización debida, por lo cual, entender que, después de un año de verse y tratarse sin supervisión en nuestro país, no es suficiente y que esto debe ser nuevamente solicitado al tribunal, es complicar las cosas en demasía. Sería más factible entender que el interés del niño estará mejor protegido si después del año la misma sicóloga que emitió el informe señalara si el menor ya está en condiciones de salir al extranjero, acompañando el documento al tribunal, lo que haría más corta la instancia de la nueva evaluación.

4. La Corte señala que no se habría fallado de acuerdo con los informes periciales, pero estimamos que ello no es así. La sicóloga recomendó la relación con el padre sin supervisión, ya que no detectaba problemas ente padre e hijo y así lo falló también la Corte Suprema, argumentando que debían construirse los lazos afectivos cercanos entre el padre y el hijo, que la madre impidió que se formaran desde la separación, para lo cual la jueza fija un año de plazo, lo cual puede ser suficiente. Pero la Corte estima que no, que cuando cambien las condiciones el menor puede viajar a Estados Unidos; ¿no sería más lógico pensar que después del año esté en condiciones de hacerlo y que sea la madre que reside en el país la que presente una solicitud oponiéndose porque las condiciones no están dadas? De esta forma, también se protege el bienestar del menor y le deja la responsabilidad a quien vive en el país de pre- 
sentar la solicitud y no al que se encuentra fuera de él.

5. Si el temor es que el padre retenga al niño en Estados Unidos, lo que es recurrente en todos estos casos, la forma de solucionarlo no es impidiendo que el menor vaya, ni negándole el acceso al padre; una buena comunicación entre las autoridades centrales de ambos países en cumplimiento de la Convención de La Haya haría que el menor volviera cuando así le correspondiera hacerlo.

Creo que debemos valorar el esfuerzo de la Corte por tratar de basar su fallo en el interés superior del niño, pero este debe ser construido con todos sus elementos y no sólo con los que se estiman importantes. Nadie se ha representado qué significa la imagen paterna para este niño, la dificultad de tenerla en todos los menores cuyos progenitores viven en diferentes países, a cargo de quien no pretende facilitar la relación con el otro padre. Creemos que el fallo es correcto al no dar la supervisión de la madre cuando las visitas se realicen en nuestro país, pero creemos que debe ser más acotado respecto a cuándo el menor podrá estar en condiciones de viajar al lugar de residencia de su padre, para comenzar a relacionarse con la otra rama de su familia. Mientras más se alargue el impedimento, más difícil será para el niño adaptarse, por lo cual es mejor fijar una fecha y si las condiciones no son las adecuadas basadas en el informe sicológico de quien lo vio con anterioridad, presentar la solicitud al tribunal y no al revés, como dice la sentencia dictada por la Corte Suprema.

Demanda de indemnización de PERJUICIOS EN MATERIA DE FAMILIA POR EJERCICIO DE MALA FE DE ACCIÓN DE impugnación. TRIBunal SAN VICente de Tagua-Tagua, 22 de mayo de 2007, Corte de Apelaciones de Rancagua, 1 DE ABRIL de 2008.

Doña N.EO.G. y don E.C.B.O. demandan de indemnización de perjuicios en contra de don A.B.S. y de doña R.E.B.S., basados en que los demandados, una vez fallecido don E.B.S., cónyuge y padre de los demandantes, respectivamente, demandaron de impugnación de paternidad y maternidad en contra de los actores, para tener acceso a la herencia dejada por don E.B.S. La demanda fue rechazada en todas sus partes, con costas, lo cual fue confirmado por la Corte de Apelaciones de Rancagua.

Loa demandantes sostienen que, invocando el artículo 197 inciso $2^{\circ} \mathrm{del}$ $C C$, se establece en forma concreta la obligación de indemnizar a quien ejerza una acción de filiación de mala fe o con el propósito de lesionar la honra de la persona demandada. Para esto, los demandantes señalan y fundamentan cómo se cumplirían cada uno de los elementos de la responsabilidad extracontractual.

Los demandados sostienen que la demandante carece de titularidad ac- 
tiva, ya que nadie puede aprovecharse de su propio dolo, y que respecto del demandante no existiría perjuicio alguno, pues lo que se señalaba en la demanda era la verdad, y que ésta fue revelada por la demandante.

Debemos recordar que cuando se dictaron las nuevas normas sobre filiación, existía el artículo 196 del $C C$, que obligaba al juez, antes de dar curso a la demanda, a verificar la existencia de fundamentos plausibles para litigar, los cuales en el caso de autos no existían motivo por el que, el juez no le habría dado curso a la demanda. Como los tribunales fueron muchas veces más exigentes que lo que indicaba el precepto mismo, $y$ muchas veces acciones de reclamación fueron desechadas, el precepto 6 fue derogado, sosteniéndose entre otros argumentos, que en caso de proceder de mala fe bastaba con el artículo 197 inciso segundo, para sancionar esas conductas.

En el caso de autos, la mala fe existía, toda vez que los demandados hicieron pública una situación que el mismo hijo ignoraba, pero con ningún objetivo, ya que de acuerdo con la nueva normativa en materia de derecho hereditario, si no existen hijos y padres, la cónyuge se llevará toda la herencia y los hermanos no tendrán derecho alguno. Ellos demandaron la impugnación pretendiendo tener derechos en la herencia, siendo que la cónyuge se encontraba viva y en caso de que se accediera a su demanda el hijo no heredaría, pero los demandados tampoco y la única heredera sería la cónyuge. No pueden alegar el desconocimiento de las normas hereditarias, ya que en caso de error en un punto de derecho, la mala fe se presume.

En el fallo de primera instancia el tribunal no acoge la demanda en cuanto a la indemnización de los daños, pues sostiene que los demandantes no especifican cuales serían, pero en todo caso al tratar de establecer el daño moral, la sentenciadora llega a las siguientes conclusiones:

a) $\mathrm{Si}$ el daño moral consiste en las incomodidades y malos ratos sufridos por la demandada a consecuencia de la acción judicial ejercida en su contra, estas molestias no son, a su juicio, indemnizables, pues no son más que una molestia normal y natural de cualquier persona al ser demandada. No estamos de acuerdo con este concepto, pues, si bien es cierto que siempre es una molestia ser demandado, cuando se refiere a una demanda que trata de señalar que no se es hijo de quien siempre se ha creído, no podemos señalar que son las mismas molestias que sufre alguien demandado en un juicio patrimonial.

b) Que si el daño moral consiste en la aflicción causada por la supuesta revelación por parte de los demandados de un secreto de familia, la revelación fue hecha por la propia demandante al absolver posiciones, y además que lo que señalaban los demandados 
era verdad; y que la verdad según la jueza no puede dar origen a perjuicios. No estamos de acuerdo con lo establecido, ya que, si bien fue la propia demandante la que lo reveló al absolver posiciones, esto lo hizo obligado por un juicio al que la llevaron los demandados, pues suponemos que la jueza no puede penar que la demandante al absolver posiciones pudiera mentir al tribunal. Que, aunque los hechos eran verdad, era una verdad que le pertenecía a los supuestos padres y a nadie más y, si bien ella lo sabía, el hecho de ver sufrir a su hijo con la revelación de estos hechos claramente constituyen un daño moral para la demandante. Toda madre que ve sufrir a su hijo, tienen derecho a ser indemnizada, ya que, si bien los padres ocultaron la verdad, nada de este sufrimiento se hubiera provocado si los demandados no hubieran iniciado el juicio de impugnación sin objetivo alguno, más que dañar a las partes, ya que no podrían tampoco tener derecho a la herencia.

c) Señala respecto del hijo que el enterarse de la verdad no puede dar derecho a indemnización; nada más errado, pues la verdad revelada en forma forzada sin que haya sido querido por sus padres, afecta el derecho a la identidad del demandante, pues él durante toda su vida ha creído ser hijo de quien en realidad no era; pero claramente sus supuestos padres así lo querían, tanto así que durante toda la vida éste fue tratado como tal y estaba configurado respecto de él la posesión notoria de que hablan los artículos 200 y 201, artículos que, incluso, le dan una mayor relevancia que a las pruebas biológicas. Por lo cual si la jueza estima que ese sufrimiento es de responsabilidad de los padres y no de los demandados, éstos últimos debieron haber probado cuáles eran sus intenciones en el juicio o, por lo menos, debieron haber podido probar la impugnación de la filiación.

d) Sin embargo, lo que más llama la atención es que la jueza en varias ocasiones reconoce que la acción de filiación interpuesta, sólo pudo tener como objeto el ánimo de perjudicar a los demandados y no el ánimo de obtener lo solicitado en la demanda, pues los demandantes ni siquiera se encontraban legitimados activamente para ejercer la acción interpuesta y actuaron, además, invocando disposiciones legales inexistentes. Con este fundamento y el artículo 197 del $C C$, bastaba 
para que la jueza entendiera que el daño existía y que era de carácter moral.

e) La jueza acoge, sin embargo, la demanda por las costas del juicio. Claramente esto no corresponde, ya que en el juicio anterior se condenó a los demandados a pagar las costas, lo que fue aceptado por los demandantes, los cuales debieron apelar si no se encontraban satisfechos por el monto, pero entendemos que a ese respecto existe cosa juzgada y que no puede, por lo tanto, volver a ser debatido.

La Corte de Apelaciones revoca la sentencia y la enmienda en ambos sentidos: a) Declara que no es posible volver a discutir sobre las costas, pues la ocasión para hacerlo era el juicio anterior.

b) En cuanto al daño su posición es totalmente opuesta, la Corte configura el daño moral, basado en que

"el demandante sufrió un daño y una aflicción en su ser íntimo de envergadura, al enterarse después de 35 años, que la persona que lo crió, lo educó y le dio cierta identidad como individuo no era su madre biológica y que su nacimiento se dio en condiciones especiales";

todo lo anterior, si bien era verdad, era una verdad que no le pertenecía a los demandados de autos y tal como señala la Corte:

"en tal caso tenían la obligación de mostrar que sus actos no estaban impregnados de mala fe, sino que tenían un fin distinto, lo que no hicieron".

c) La verdad debería haber sido dicha en forma particular, no era necesario ninguna instancia judicial, ya que no se sabe cuáles eran los objetivos de los demandados, ya que ellos sabían que no tenían derecho alguno a la herencia. Tal como señala la Corte:

"si bien la verdad es en sí misma un bien superior, es cierto que su revelación en determinadas circunstancias puede ser fuente de obligaciones, ello acontecerá cuando aquella revelación cause un daño injustificado a quien se ve impactado con el conocimiento de la misma y que el contarla no obedece a obligación alguna”.

d) Los daños estimados por la Corte se traducen en la pérdida de su identidad y el hecho de que el demandante de esta causa, va a tener que adaptarse a esta nueva situación y en cierto modo también recomponer su relación con su supuesta madre. 
e) Si bien estamos de acuerdo en lo anterior, creemos que la madre también sufrió daños morales, porque el fundamento de éstos no es el que ella ya sabía la verdad, sino que ver y sentir el sufrimiento de su hijo es lo que en nuestra opinión

puede ser considerado también daño moral, aunque la Corte no lo reconoce, ya que señala que al enterarse de la verdad el impacto no puede ser como el de su hijo; pero el sufrimiento del hijo si es constitutivo de daño moral para una madre. 